\title{
Three Lessons for Monetary Policy from the Panic of 2008
}

James Bullard

This article is a modified version of a presentation given at the Federal Reserve Bank of Philadelphia's policy forum "Policy Lessons from the Economic and Financial Crisis," December 4, 2009. The presentation was made during a panel discussion that also included John Taylor and N. Gregory Mankiw.

Federal Reserve Bank of St. Louis Review, May/June 2010, 92(3), pp. 155-63.

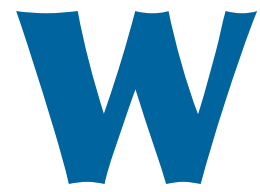

e have been wrestling with one of the most severe recessions in the post-World War II era; moreover, it has been accompanied by a widespread financial crisis. After unprecedented policy responses, there are signs of recovery on both fronts. So, it is not too early to take stock of our actions and attempt to learn lessons from our recent past-lessons for monetary policy, financial regulation, and other aspects of the crisis. My objective here is to focus on lessons for monetary policy alone and leave discussion of regulatory issues and financial markets for another day.

\section{AN OVERVIEW OF THE CRISIS}

First, let me explain the nature of the crisis as I see it. My narrative is a little bit different from what some people describe, so it's important that I establish it before I talk about any lessons to be learned. I think that history will assert that there was a panic in the autumn of 2008, and maybe that's fair. But this crisis actually began much earlier: The onset is usually dated as August 2007, with many key events along the way.

For instance, in October 2007, equity prices actually peaked. The initial reaction by policymakers, as well as markets, then, was to view the crisis as perhaps less severe than it actually turned out to be. In March 2008, Bear Stearns was purchased by J.P. Morgan with Fed assistance. The U.S. economy continued to grow through the second quarter of 2008. We did have a commodity price spike in the second quarter of 2008: $\$ 100$ per barrel of West Texas intermediate crude oil in March. Then the price of oil went up another $\$ 45$ from there, which is well above, in real terms, the 1980 peak in oil prices.

The economy began to slow down in the third quarter of 2008. And the contracting economy, both in the United States and abroad, intensified the financial crisis, which at that point had been roiling for an entire year. But because the economy started slowing, the crisis greatly worsened during the autumn; dozens of firms worldwide required assistance to avoid bankruptcy in the fourth quarter of 2008. In that quarter and the first quarter of 2009, major economies worldwide contracted.

James Bullard is president of the Federal Reserve Bank of St. Louis. The author appreciates the assistance and comments provided by colleagues at the Federal Reserve Bank of St. Louis, especially Chris Waller, senior vice president and director of research, and Bob Rasche, executive vice president and senior policy advisor. Marcela M. Williams, special research assistant to the president, provided assistance.

(C) 2010, The Federal Reserve Bank of St. Louis. The views expressed in this article are those of the author(s) and do not necessarily reflect the views of the Federal Reserve System, the Board of Governors, or the regional Federal Reserve Banks. Articles may be reprinted, reproduced, published, distributed, displayed, and transmitted in their entirety if copyright notice, author name(s), and full citation are included. Abstracts, synopses, and other derivative works may be made only with prior written permission of the Federal Reserve Bank of St. Louis. 
This is a little bit different from what you sometimes hear, but it is predicated on the idea that the crisis had been going on for a long time before the economy actually started to contract. ${ }^{1}$

\section{The Monetary Policy Response}

Basically, the Federal Reserve's monetary policy response to the crisis can be divided into three parts. The first part was a wide array of collateralized lending programs, which, in my discussion here, I am going to lump all together and call liquidity programs. After September 2008, these were funded by reserve creation-that is, by printing money. These programs are temporary in nature, and I don't view them as an inflationary threat.

The second part was to move the target policy interest rate toward zero-in fact, very close to zero. The Fed was actually very aggressive in lowering rates during the last part of 2007 into the first part of 2008.

The third part of the policy response was an aggressive asset purchase program. I'm going to put this topic under the title "quantitative easing." This response was also funded by reserve creation, like the liquidity programs, but in this case the balance sheet effects are far more persistent. I think that this program creates a medium-term inflation threat in a way that the liquidity programs do not. I will continue this discussion in the next section.

\section{THREE LESSONS}

I will focus on three lessons for monetary policy that have emerged from recent events: They have to do with understanding that (i) the role of lender of last resort can be carried out on a grand scale; (ii) quantitative easing can substitute for policy rate easing after the zero bound is encountered; and (iii) the connections between asset pricing and monetary policy must be a top priority going forward.

\footnotetext{
1 This episode has been described as the "perfect storm": In sum, the financial crisis began in 2007-exacerbated by the spike in commodity prices in the first half of 2008-and the economic slowdown revealed itself in the autumn of 2008, at which time panic ensued worldwide.
}

\section{Lesson 1: Lender of Last Resort on a Grand Scale}

My first lesson is about the Fed's role as lender of last resort on a grand scale. So what is the lesson? It is that the Fed's ability to act decisively in a crisis through its lender-of-last-resort function far outstrips previous conventional wisdom. I think that the response has been more creative and much more substantial than people would have imagined: If you had a conference before the crisis to discuss the lender-of-last-resort function, I don't think the recent actions by the Fed would have been predicted.

Going forward, I think that these liquidity programs need to be carefully evaluated. That's a call for our research community to study them closely, and John Taylor has been a leader in analyzing the effectiveness and implications of these programs (Taylor and Williams, 2008, 2009). One concern is that the scale of these liquidity programs may unintentionally be setting up expectations of future intervention, and I believe we need to think carefully about that. How are markets expecting we're going to react in future crises? Is that something we desire or not? And how should we account for that?

The lender-of-last-resort function-lending extensively in response to a crisis-has been an integral part of central banking for the past 200, maybe 300 years. It is all collateralized lending, and the basic premise is that it is necessary to provide a lot of liquidity to markets in the event of a crisis.

The Fed was very innovative in this area. We developed a wide array of liquidity programs in 2007-08 that were all designed to improve market functioning. These programs were always meant to be temporary in nature and are therefore priced in such a way that markets will not find them attractive once the crisis passes. And that is happening now on a large scale: As market functioning improves, these programs become less necessary.

Some of these programs are within the Fed's traditional purview; some were authorized under the so-called 13(3) provision in the Federal Reserve Act, which allows the Fed to lend to other parties 


\section{Figure 1}

\section{LIBOR-OIS Spread}

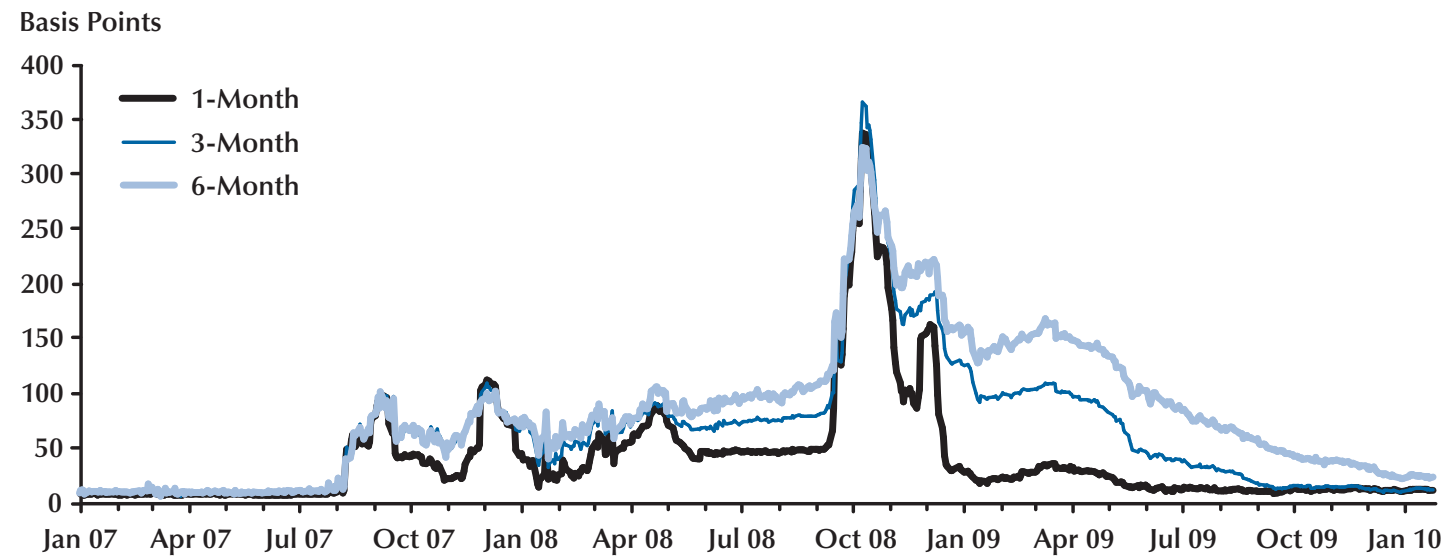

NOTE: Data are through January 25, 2010.

SOURCE: Financial Times and Reuters.

in unusual and exigent circumstances. It's a wide variety, but all programs are intended to improve market functioning. Some may have worked better than others, of course, and so we should evaluate these programs carefully. As we do that, we should keep in mind that, simultaneous to the Fed's collateralized lending, many government guarantees were coming into play. As future research addresses this topic, it will be essential to evaluate the effect of the government guarantees in tandem with the effect of providing liquidity to the markets.

But regardless of how these individual programs perform, by many metrics they are considered an overall success. Although we're not completely back to pre-crisis levels, global financial markets are less strained than they were.

Figure 1 shows a familiar picture: the LIBOR-OIS spread dating back to January 2007. Again, the crisis started in earnest in August 2007, the point at which this LIBOR-OIS spread jumps up. That jump was actually considered gigantic at the time, although it turned out to be relatively small, as events unfolded in the autumn of 2008.

These spreads have decreased substantially, even though they are not back to where they were during the first half of 2007. ${ }^{2}$ This reversal is often attributed to the liquidity programs. You could argue about it, but I think the point is that the liquidity programs, as a pillar of the monetary policy response to the crisis, are certainly being used a lot less intensively today than they were even six months ago. The Fed's core idea is to let these programs continue to wind down naturally and to end the authority of the 13(3) provision for emergency programs in 2010.

Figure 2 shows the volume of reserves supplied to financial firms and markets through liquidity facilities. The peak exceeds $\$ 1.6$ trillion. This is what I meant by "lender of last resort on a grand scale." On September 11, 2001, we had about $\$ 40$ billion of reserves in the system and we almost doubled that to about $\$ 75$ billion. $^{3}$ At the time, we thought that was a gigantic sum. But this recent level of $\$ 1.6$ trillion of lending to firms and markets in response to this crisis is truly a monumental attempt to alleviate liquidity constraints in the markets and to get past this crisis-and one metric for measuring how large this crisis really was.

2 In fact, these spreads are quite close, with the exception of the 6-month spread.

3 This figure is for total reserves adjusted for reserve requirements. 


\section{Figure 2}

\section{Short-Term Lending to Financial Firms and Markets}

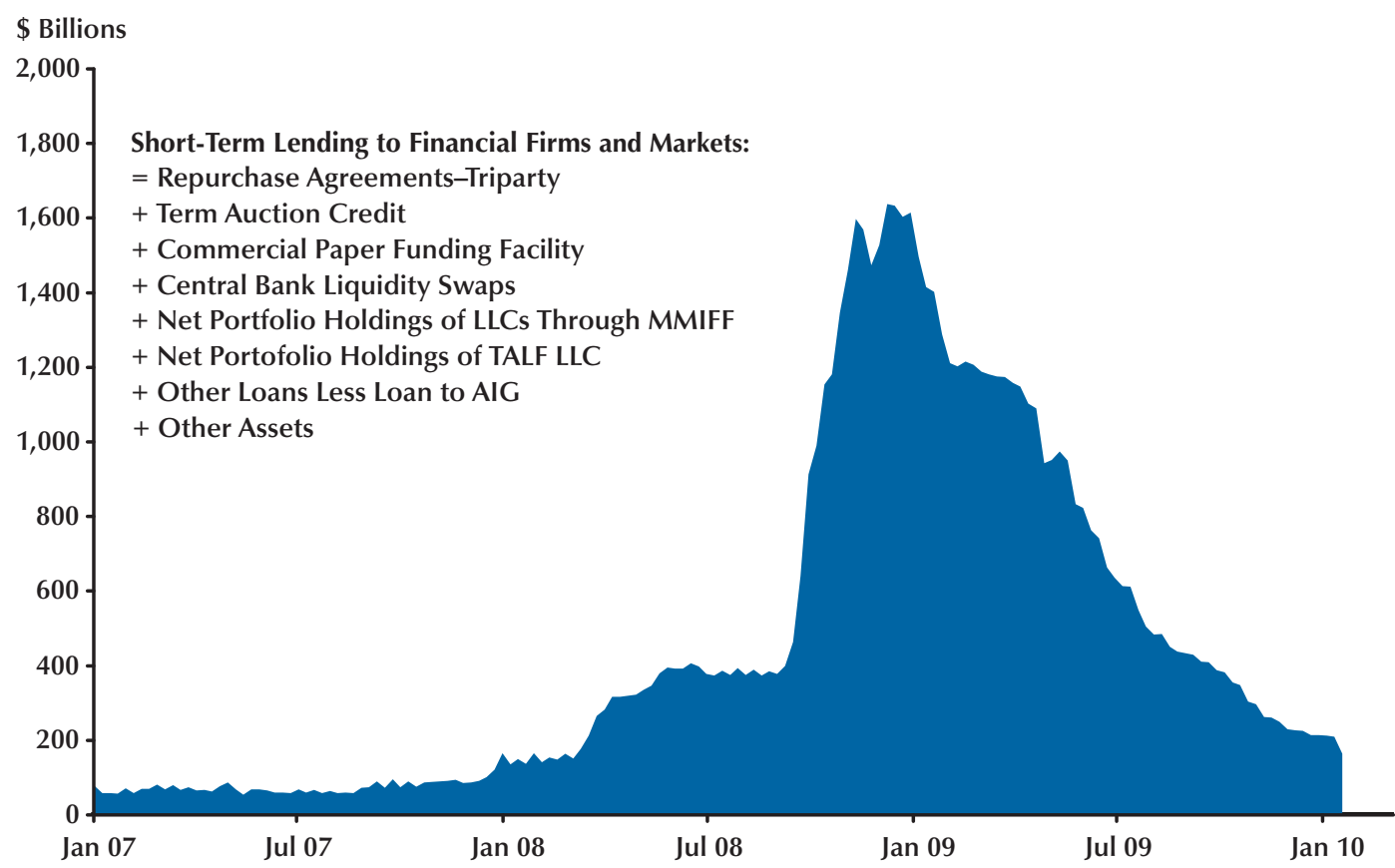

NOTE: Data are through January 10, 2010. MMIFF, Money Market Investor Funding Facility; TALF, Term Asset-Backed Securities Loan Facility.

SOURCE: Federal Reserve Board, H.4.1.

Again, these programs are priced to be unattractive in normal circumstances, which is why they have declined so rapidly from their peak of $\$ 1.6$ trillion to under $\$ 300$ billion. Firms do not want to use these programs unless they really need them. The expectation is that these programs will cease to exist by the first quarter of 2010 if financial conditions continue to improve; at that point, the Fed's short-term lending to ensure liquidity will return to a minimal level.

This lesson, then, is that these programs are much larger and more varied than could have been anticipated before the crisis. It is time to evaluate which ones worked and which ones didn't and to think much more carefully about the ramifications of the lender-of-last-resort policy, which has not often been as prominent a topic in the research world as other aspects of monetary policy. We also need to assess whether we have unwittingly set up expectations of future intervention that could be influencing markets today.

\section{Lesson 2: The Several Faces of Monetary Policy}

The United States has not had policy rates at (or essentially at) zero since the 1930s. Yet, even in this current environment, the Fed has not ceased to function. The second lesson is that monetary policy can be conducted by different means. Normally, we think of monetary policy as interest rate adjustment, but when you reach the zero bound in nominal interest rates, you have to adjust monetary policy in other dimensions and that's exactly what the Fed has done. There may have been some doubt-before this recent episodeabout the ability of the Fed to conduct a business 
cycle stabilization policy with policy rates near zero. But I think this episode clearly reveals that the Fed is perfectly capable of doing so.

In my opinion, analogous to interest rate policy, quantitative policy should be state contingent; that is, it should adjust according to incoming information on the state of the economy. And these types of policy do have some relation to each other. Although they are different, I think that any quantitative policy should be conducted in a manner that's analogous to interest rate policy. To me, that means adjusting the policy according to incoming information.

Since its March 17-18, 2009, meeting, the Federal Open Market Committee (FOMC) has explicitly stated that it will keep the federal funds rate target near zero for an "extended period." Any movement away from that position will be contingent on both inflation and real economic developments. But my question is this: How should the FOMC conduct business cycle stabilization policy during the period of near-zero policy rates? And the answer is that there are many interest rates and many assets that the Fed can influence.

The FOMC communicated its plans to make more than \$1.7 trillion in outright asset purchases in a series of announcements beginning about December 2008. The purchases are agency debt (in this case, "agency" means Fannie Mae and Freddie Mac), agency mortgage-backed securities (MBS), and longer-term Treasury securities. The bulk of these purchases are agency MBS. Again, this is being financed by reserve creation, or printing money. Consequently, the monetary base has more than doubled, creating a medium-term inflation risk.

This point deserves some illumination. According to monetary theory, very large increases in the monetary base are inflationary. And the inflationary effects of very large increases in the monetary base depend on at least two factors: One factor is private sector expectations of the future level of the monetary base. As always, in macroeconomics and monetary theory, expectations are very important. With large increases that are expected to be temporary, as they are with the liquidity programs, I don't believe there is much of an inflationary threat. But large increases in the monetary base that are expected to be permanent—or at least more persistent-may indeed be inflationary. Increases in the monetary base that are associated with asset purchases fall into this more-persistent category, which is why this aspect of current policy poses a medium-term inflation risk.

The second factor that would affect the medium-term inflation risk is the speed with which the increases in the monetary base translate into increases in the money supply. The monetary base is not the money supply: Before monetary increases can affect inflation, the "money" must be incorporated into ordinary transactions. That is not occurring right now; the speed with which the monetary base is being translated into changes in the money supply is very slow at this point. This often happens when the economy slows down as rapidly as the U.S. economy has. But we can expect that this process will start to accelerate and that may affect the medium-term inflation risk.

Figure 3 shows the Fed's balance sheet in a particularly instructive way. The area above the black line is a duplication of Figure 2: the total volume of the liquidity programs. As I said previously, that component of the balance sheet is not worrisome; it does not create a medium-term inflation risk.

The dark blue area below the black line shows the more traditional holdings of the Federal Reserve, such as Treasury securities, and the light blue area under the black line is the MBS purchase program, which has grown very large. The dotted black line projects how this part of the balance sheet will continue to grow through the first quarter of 2010. Under current conditions, the size of the balance sheet will increase to about $\$ 2.4$ trillion. And again, unlike the liquidity programs, these purchases will not run off in a period of months because these assets have much longer maturities: seven to ten years. In this case, we're talking about mortgages. And so we would expect this expansion of the monetary base, then, to be much more persistent and not likely to dissipate in a timely fashion.

Moving on to the asset purchases as quantitative easing: Again, the FOMC moved its policy 


\section{Figure 3}

\section{Composition of the Federal Reserve's Balance Sheet and Projected Path Through March 2010}

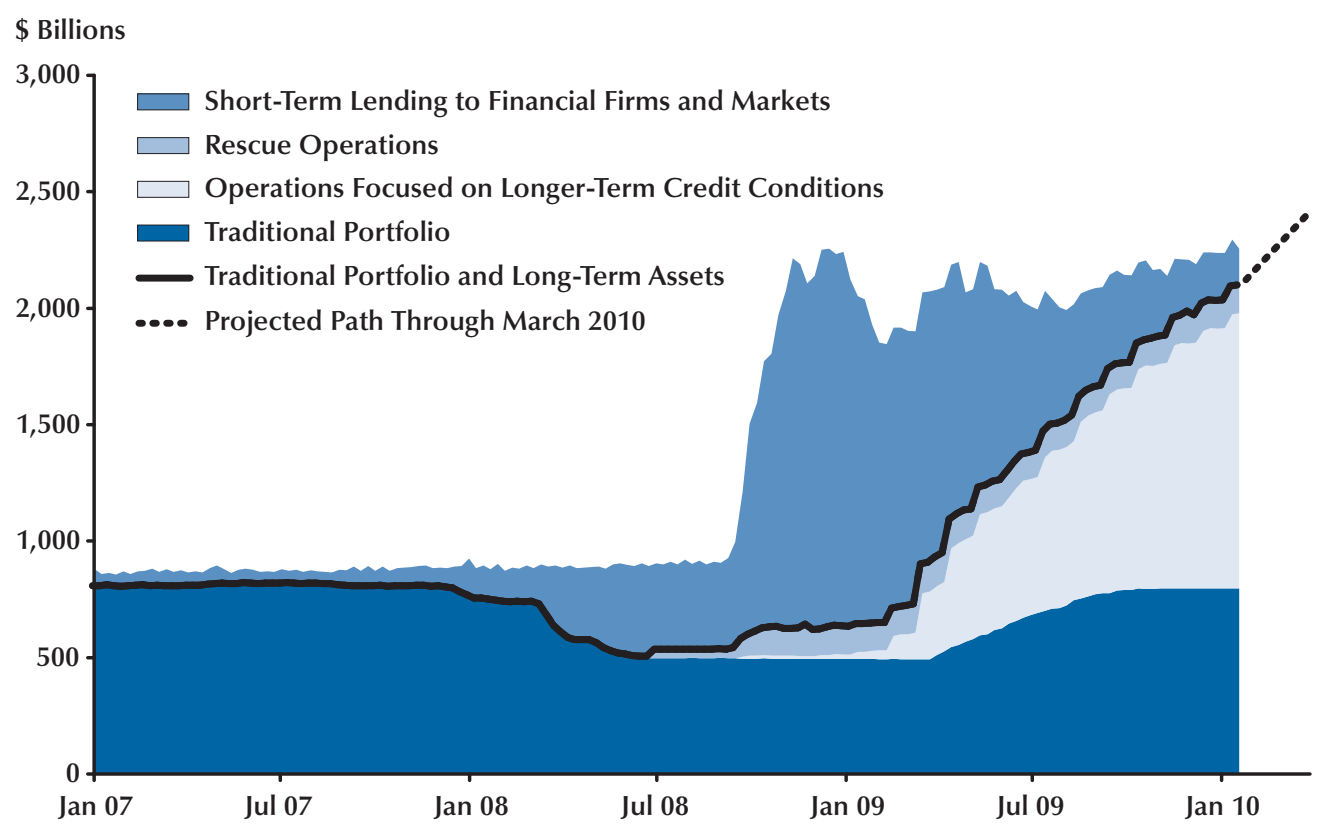

SOURCE: Federal Reserve Board, H.4.1.

rate toward zero in December of 2008, and right after that began this asset purchase program-in fact, in the first month of 2009. I think that this program has been regarded as successful, as it further eased monetary conditions after the zero bound was encountered. So in some sense, the asset purchase program substituted for additional easing that could not be done through the policy rates, since the policy rate had come very close to zero. So a natural way to run monetary policy going forward would be for the FOMC to continue to adjust the asset purchase program while the policy rate remains near zero.

I like to think of asset purchases in terms of state-contingent policy. When we adjust interest rates, we always do so in response to economic conditions: readings on inflation and on the real economy. The famous Taylor rule is one example of that, but there are many other examples, and it's a natural way for the central bank to operate.

The asset purchase program that we have in place right now does not have this state-contingent character. What we on the FOMC did as a committee is simply announce that $\$ 1.725$ billion of assets would be purchased by the first quarter of 2010. I don't see anything optimal about simply announcing a number and buying that amount of assets. It may be helpful for monetary policy going forward to think more in terms of adjusting this program as macroeconomic information arrives. That's what you would do with the Taylor rule. Although there's no guarantee at this point that current quantitative policy will become statecontingent, it seems to me if you're going to have two policy instruments in place, you should have them operate in the same fashion: both adjusted in response to incoming information.

And, with the policy rate near zero, the asset purchase program could very easily dominate policy for some time. In fact, I suggest staying active in the market for agency MBS. If encouraging information on the economy arrives after the first quarter of 2010, then we could consider 


\section{Figure 4}

\section{Timeline of Monetary Policy}

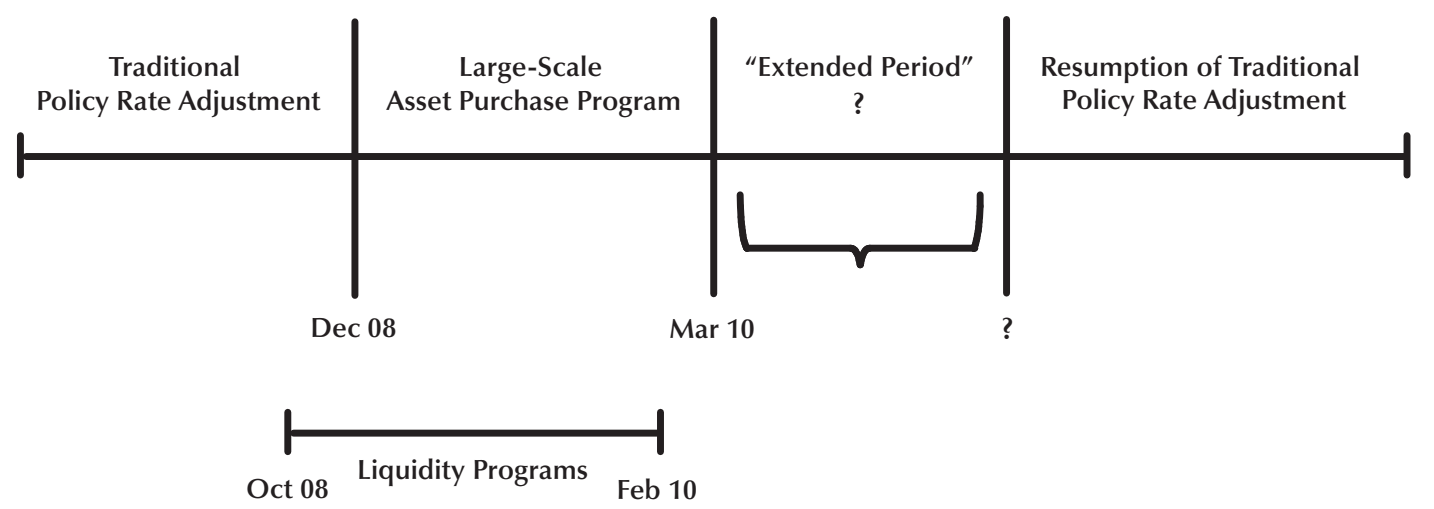

removing some accommodation through asset sales. We certainly wouldn't want to do that in blanket fashion; this is all about adjustments at the margin, so you'd adjust a little bit through asset sales. On the other hand, if discouraging economic news came in, then you could consider additional asset purchases. This would allow monetary policy to remain active, responding to shocks during the period of near-zero interest rates.

Figure 4 shows a timeline. Traditional policy rate adjustment, as it's been practiced in the United States and around the world over the past 20 to 25 years and maybe quite a bit longer than that, is noted on the left side. The liquidity programs appear beneath and extend from October 2008 until the first quarter of 2010-February or March 2010. These liquidity programs were a response to the crisis, but they are set off to the side because they're not part of the traditional policy response or an attempt to run stabilization policy. Once the rate approached zero in December of 2008, we began our large-scale asset purchase program, which is shown as continuing through March 2010. The timeline then shows a period with some question marks that refers to the extended period language that the FOMC has adopted. And as I said, we will continue to keep rates low for an extended period, and what we do in the future will depend on how the data come in on the economy.
But during this period, you could also adjust your asset purchases in one direction or the other as information arrives, perhaps before you want to make a decision on the interest rate margin. And then at some point down the road-and I'm being very cagey here, by putting a question mark on that point-you'd make a decision on the interest rate; you'd return to a traditional policy rate adjustment and would go on from there. So this is just a suggestion about how to think about policy in 2010 and beyond.

In summary, the asset purchase program is very large. It is being financed by reserve creationi.e., printing money. It is generally considered successful. And it has substituted for easing that cannot be accomplished through the policy rate. Longer-term interest rates generally fell as aspects of the program were communicated in Chairman Bernanke's announcements in late 2008 and then in further announcements in the first part of 2009. And I think that the FOMC could use the program to respond to incoming information on the economy during the period of near-zero interest rates.

\section{Lesson 3: Bubbles}

The third lesson is about asset price "bubbles." (I'm placing bubbles in quotation marks because I'm trying to exorcise the bubble language. I have been unable to do it so far.) It is a very serious 
issue for monetary policy and has been debated extensively over the past 15 years. But now we are having a renewed and more intense debate. The main problem in thinking about this issue appears to me to be that it is hard to see what was wrong with the previous policy, given conventional ideas about what we attempt to accomplish with policy.

We have had two decades with two bubbles. The first one was in the 1990s, and the second one was in the current decade. In both cases, after the 1991 recession, and again after the 2001 recession, we had jobless recoveries; and it took a long time before the Fed decided to raise rates and come off their cyclical lows in either of those cases. In the 1990s we had the so-called "dot-com bubble." In the 2000s we had the "housing bubble," and the drag on the economy from the housing decline has been really severe since 2006 .

Despite this, the monetary policy outcomes during the past two decades-up to the current recession-actually have been quite good. Unemployment hit lows of 3.8 percent and 4.4 percent, respectively. In the current decade, inflation has been low and stable. In terms of the conventional ideas about what monetary policy tries to accomplish, those years were quite good. Still, even without an increase in inflation, the asset price misalignment seemed to have caused significant problems for the macroeconomy, and that may mean that we should put more weight on asset prices going forward.

Now, there has been debate on this, and this is my final point. There is a policy debate on this topic and there is an academic debate. The policy debate has made good points: that it is difficult to identify asset price misalignments in real time and that interest rates are a blunt instrument to respond to asset price misalignments. I think not all bubbles are bad. Consider the "tech bubble" of the 1990s. A lot of good technology was developed then, even though it seemed to be an asset price misalignment. And this is what the policy debate has said.
There is also an academic literature on this issue, and it generally does not come into the policy discussion. The literature is about multiple equilibria: There is a set of expectations and a set of prices that will clear markets, but there is another set of expectations and another set of prices that will also clear markets. And, as described in the literature, the objective is to adopt a policy to quash these multiple equilibria so that you're left with only the fundamental equilibrium. At that point, the economy will bounce along according to the actual shocks that hit the economy.

In my mind, this is a more sophisticated way to think about "asset bubbles" and how to respond to them. According to this literature, one example of a policy that works fairly well is for monetary policy to react aggressively to shocks. If this is done, then multiple equilibria-specifically, those that are not based on fundamentals-are discarded and the economy is kept near its fundamental equilibrium. I interpret that as the best policy to follow to avoid problems with bubbles.

So if we approach this issue seriously and intensify this debate further, we may have to entertain these sorts of ideas and step up our analysis of this issue.

\section{CONCLUSION}

The recent crisis has been challenging, to say the least. But we have the opportunity to evaluate our responses and the effects of those responses. To sum up: The first lesson is that the lender-oflast-resort function has proven much more flexible and more powerful than previously believed. The second lesson is that the asset purchase program has shown that active stabilization policy is possible with the policy rate at zero. And the third lesson is that clearly the issue of "asset price bubbles" is a hard one for monetary policy and may require new and innovative analysis. 


\section{REFERENCES}

Taylor, John B. and Williams, John C. “A Black Swan in the Money Market.” American Economic Journal: Macroeconomics, January 2009, 1(1), pp. 58-83.

Taylor, John B. and Williams, John C. “Further Results on a Black Swan in the Money Market.” Unpublished manuscript, May 2008;

www.stanford.edu/ johntayl/Taylor-Williams-Further\%20Results\%20on\%20Black\%20Swan.pdf. 
